\title{
The Trends of Neonatal Mortality Rate Among South East Asia Countries from 2000-2017
}

\author{
Sani Rachman Soleman* \\ Department of Public Health, Faculty of Medicine, Islamic University of Indonesia \\ *Corresponding author, email: sani.rachman@uii.ac.id
}

Received: 12/03/2020; published: 29/09/2020

\begin{abstract}
Background: Neonatal MortalityRate (NMR) reflects the quality of health services provided by the government. It is very important to disclose the health system capability of each country in managing mother and child health programs because it is an essential health policy that should be prioritized. The health system capability of a country will determine the welfare and social guarantee because most of NMR causes are preventable. Several components such as maternal factors, neonatal and health services were determined as predictors of NMR. The objective of this study is to compare neonatal mortality trends among eight South East Asia Countries (SEAC) from 2000 to 2017. Method: A cross-sectional design was used to analyze the data regarding the causes of neonatal death between 2000 and 2017. Data were taken from World Health Organization Maternal Child Epidemiology Estimation (WHO MCEE) database.The collected data were live birth; neonatal mortality rate; and the big five of neonatal mortality etiologies in the eight SEAC. Data were then analyzed descriptively with line chart to describe the trend of NMR. Result: This study found that Indonesia had the highest neonatal mortality rate, yet the trend decreased gradually from 102.700 in 2000 to 60.986 in 2017, followed by Philippines, Vietnam, Myanmar, Cambodia, Thailand, Laos, and Malaysia respectively. On the other hand, the trend of live birth was the lowest in Indonesia and the highest in Philippines. According to the data regarding the leading cause of NMR, preterm birth was the major cause of neonatal mortality followed by birth asphyxia and congenital defects. Conclusion: Indonesia has the highest mortality rate, yet the etiology such as as premature birth, asphyxia, and congenital disorder is similar to the other eight countries.
\end{abstract}

Keywords: neonatal mortality rate; premature birth; birth asphyxia; congenital defects; southeast asia countries

Copyright $(\subset) 2013$ Universitas Ahmad Dahlan. All rights reserved.

1. Introduction

Since September 2015, United Nation has been implementing Sustainable Development Goals (SDG's) that encompasses 17 primary goals as a road map in social justice, equality and prosperity (1). One of the goals is ensuring healthy lives as well as promoting well-being for everybody at all ages including maternal and child health (2). Between 2000 and 2015, global maternal death had declined by $37 \%$ and child mortality dropped by $44 \%$. However, it is imperative to be noted that 303,000 mothers died during pregnancy or delivery process and 5.9 million children died due to preventable causes (2). According to World Health Organization (WHO) report on 2018, there was a declining trend of Neonatal Mortality Rate (NMR) from 2000 to 2017 for $41 \%$ or 37 per 1000 live birth to 18 per 1000 live birth or 5 million neonates died in 2000 to 2.5 million in 2017 (3). Several aspects were identified as the primary risk factors of NMR such as social-demographic, maternal health, neonatal aspect, delivery factors including pre-delivery, during and postdelivery (4). Furthermore, the crucial issues of NMR that should be addressed are the complications of early delivery such as premature birth, asphyxia, congenital defects, and sepsis of severe infections (4). 
The condition of NMR in South East Asia Countries (SEAC) is similar to other WHO regions around the world. Southeast Asia Countries as developing countries face the global public health challenge in fixing the root causes of $\operatorname{NMR}(2)$. It was estimated that the number of neonatal death in SEAC was around 200,000 per year or 1-3 per 1000 live birth (5). A study explained that among SEAC, Myanmar had the highest prevalence of NMR, that was 32 per 1000 live birth followed by Timor Leste, Cambodia, and Laos respectively (24 per 1000, 22 per 1000 and 21 per 1000 live birth)(5). Meanwhile, the countries with the lowest NMR were Singapore, Malaysia, and Brunei respectively (1 per 1000, 3 per 1000 and 4 per 1000) (5). The number of population in a country should also be considered as it may affect the rank among countries. For instance, although there were 17 cases of NMR per 1000 live birth in Indonesia, this country is known as the most populated country in SEAC (4). SEAC, as a limited-resources region, faces serious issues regarding the common causes of NMR such as preterm birth, asphyxia, growth retardation, and congenital anomalies (5). These causes are preventable and treatable by applying appropriate approaches to prevent babies from death. Some approaches that can be performed are access to life-saving interventions for maternal and neonatal as well as the continuum of care during pre-pregnancy, antenatal, intra-partum, delivery, the postpartum and postnatal period for mothers and their babies(6).

NMR reflects the capability of health policy and strong commitment from the government to handle, fix, and ensure the health quality services as the main component of SDG (1). The government should take action and advocate to guarantee the maternal, neonatal, and children health. The challenges and opportunities vary for each country as there are many influencing aspects like policy setting, economic, social, security, budget allocation, and the wide-range area around the continent. For example, in SEAC, Timor Leste, as a poor country requires budget allocation for the safe delivery of mother and babies (5). On the contrary, Singapore as one of the developed country is more advanced in dealing with NMR or maternal health (5). One of the policies that can be proposed to decrease the gap is by empowering and strengthening the national health insurance and the quality of primary care services (7-9).

World Health Organization (2020) has developed a new guideline that provides several recommendations on improving early child development and minimizing neonatal death. The guideline encompasses providing responsive caregiving during the first year of life, promoting early learning during the first year of life by parents or caregiver to engage the children with community, integrating caregiving and nutrition interventions for optimal growth and development, and supporting maternal mental health by psychological interventions. Neonatal mortality rate is a pivotal element that must be addressed by the government because it is correlated with policy and sustainability in health system particularly among ASEAN countries. The problems are complicated and interconnected so the government must allocate budget and resources to handle those problems. Therefore, this study attempts to give a brief description of the etiology of NMR and the trend of NMR among ASEAN countries in handling and fixing the problems collectively.

\section{Methods}

A descriptive cross-sectional study was used to analyze the secondary data of neonatal death causes between 2000 and 2017. The data were taken from World Health Organization Maternal Child Epidemiology Estimation (WHO MCEE) database that can be accessed

https://www.who.int/healthinfo/global_burden disease/estimates/en/index2.html. The three big data included neonatal, post neonatal, and under-five mortality rate. The data were determined based on WHO's regions and countries. The causes of death data were divided into 14 categories as follows: HIV/AIDS, diarrhea, tetanus, measles, meningitis/encephalitis, malaria, acute respiratory infections, premature baby, birth asphyxia and birth trauma, sepsis and another newborn infections, congenital defects, non-communicable diseases, and injuries. This study involved only eight SEAC as these countries have the biggest population and the highest NMR in SEAC. In terms of the causes of NMR, only the top 5 causes in each country were analyzed as those cases were the most prevalent in SEAC. The rest of the causes were not analyzed because there were only few cases reported in SEAC between 2000 and 2017. We did not propose any ethical clearance as the data we

The Trends of Neonatal Mortality Rate Among South East Asia.....(Sani Rachman Soleman) 
obtained are open sources. We presented these data using a line graph with Microsoft Excel 2016.

\section{Results and Discussion}

3.1 Results

Figure 1 shows that Indonesia had the highest neonatal mortality death among SEAC countries followed by Philippine and Myanmar respectively. The prevalence in 2000 was 102.700. Hereafter, the trend slowly decreased each year up to 60.986 in 2017, almost double up from the beginning. The country with the lowest trend was Malaysia where the trend decreased from 2690 in 2000 to 2295 in 2017.

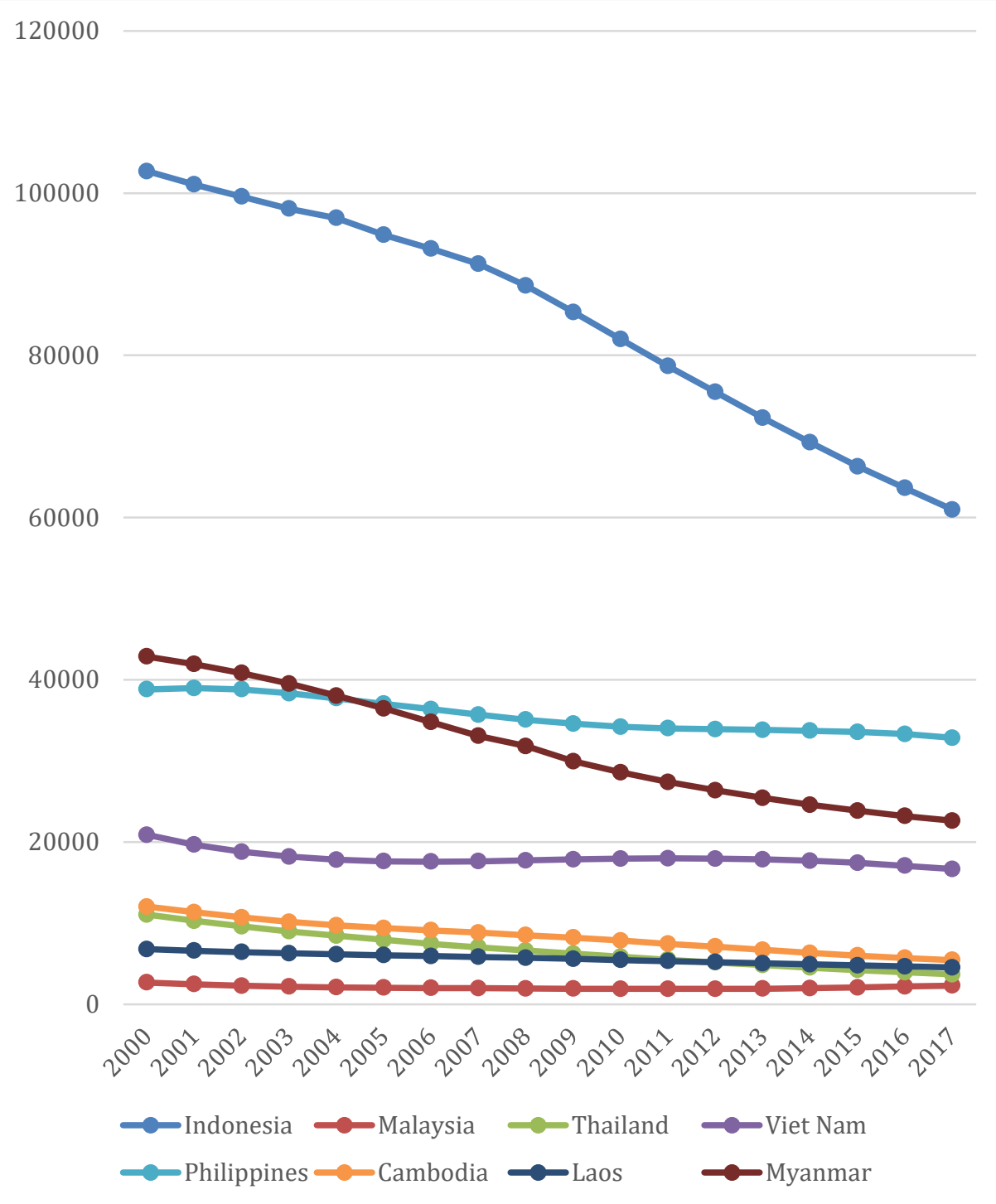

Figure 1. Neonatal Mortality Trend among South East Asia Countries

Figure 2 reveals that Indonesia was at the top of live birth rate in $2017(4,912,756)$ followed by Philippines $(2,411,184)$, Vietnam $(1,570,352)$, and Myanmar $(940,354)$ respectively. Meanwhile, the country with the lowest trend was Laos $(160,698)$. 


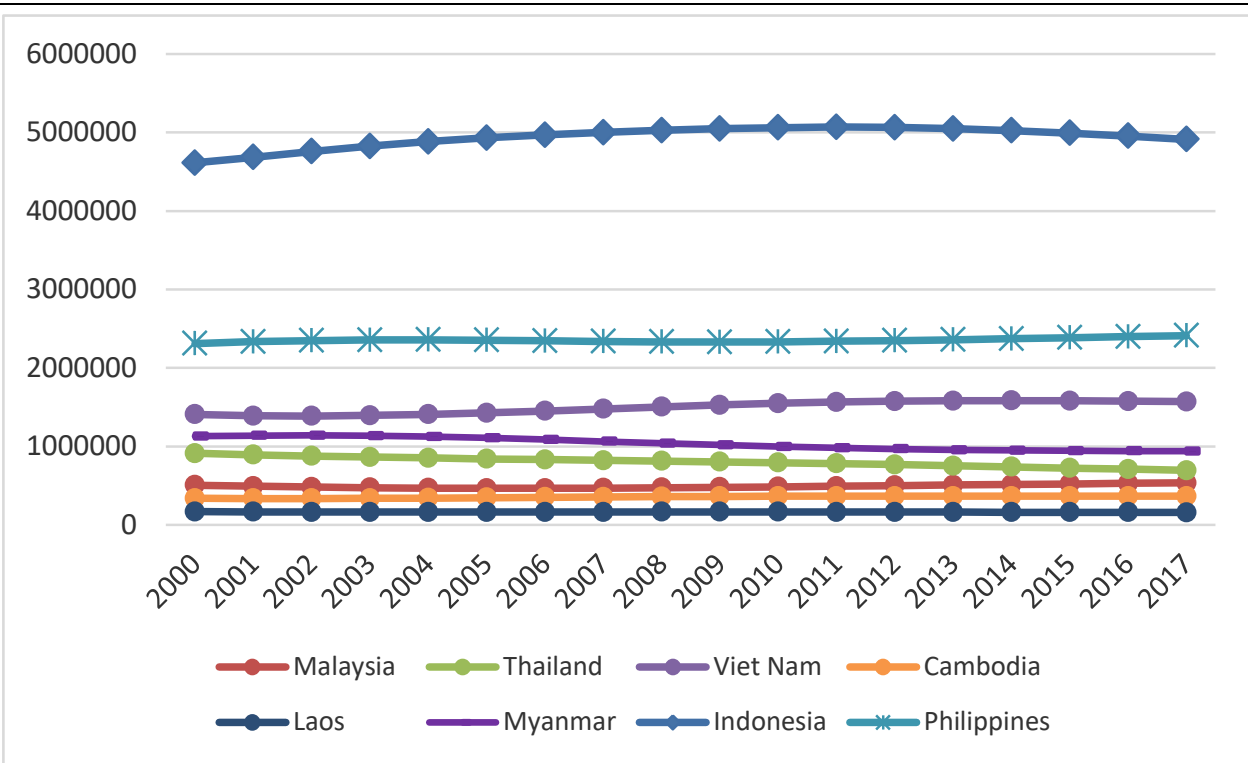

Figure 2. Live birth among South East Asia Countries

Figure 3 illustrates the trend of neonatal death causes in Indonesia. Premature birth still has been the primary problem since 2000 , yet the prevalence decreased significantly in 2000 to 2017 (32.953 to 21.147). The trend is followed by birth asphyxia (27.794 to 13.843), congenital defect (11.740 to 10.702), and ARI (6514 to 3362).

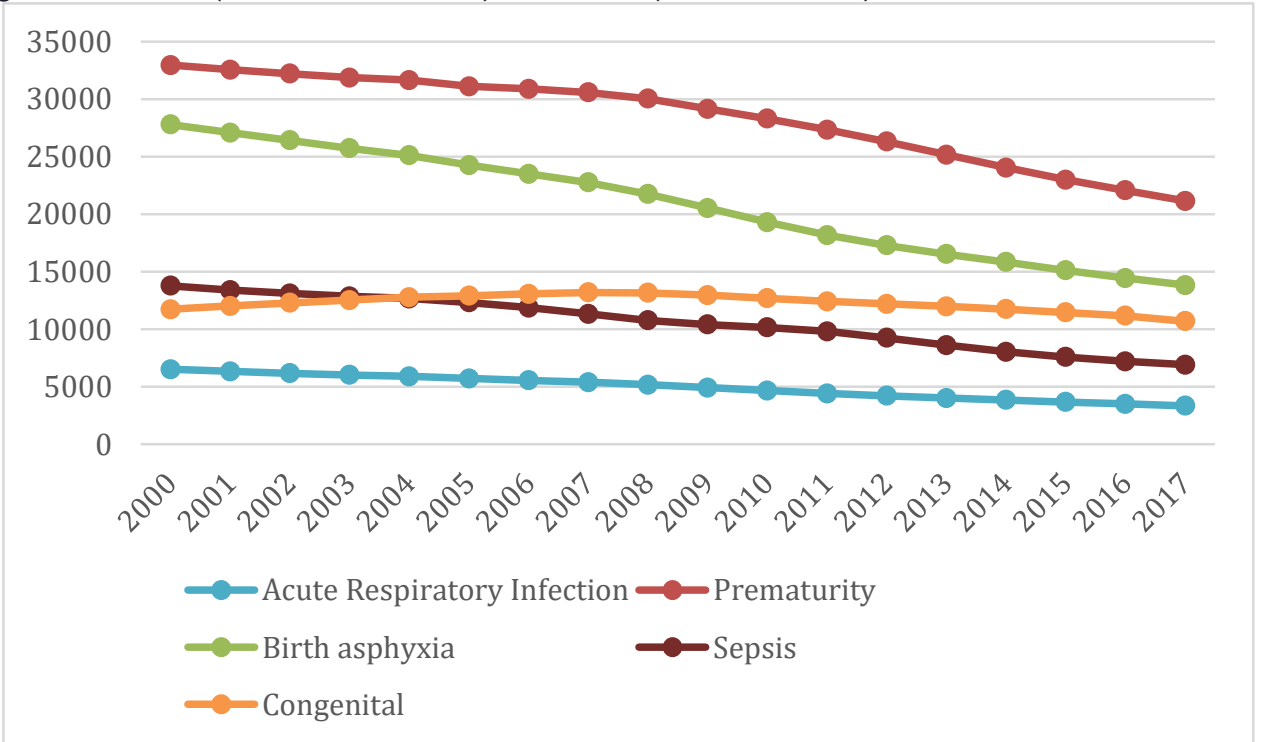

Figure 3.The leading causes of Neonatal Mortality Trend in Indonesia

Most neonatal death in Philippines between 2000-2017 were caused by premature birth (13.598 to 10.189), birth asphyxia (9717 to 7839$)$, congenital disorder (5081 to 5509), and ARI (2575 to 1942). 


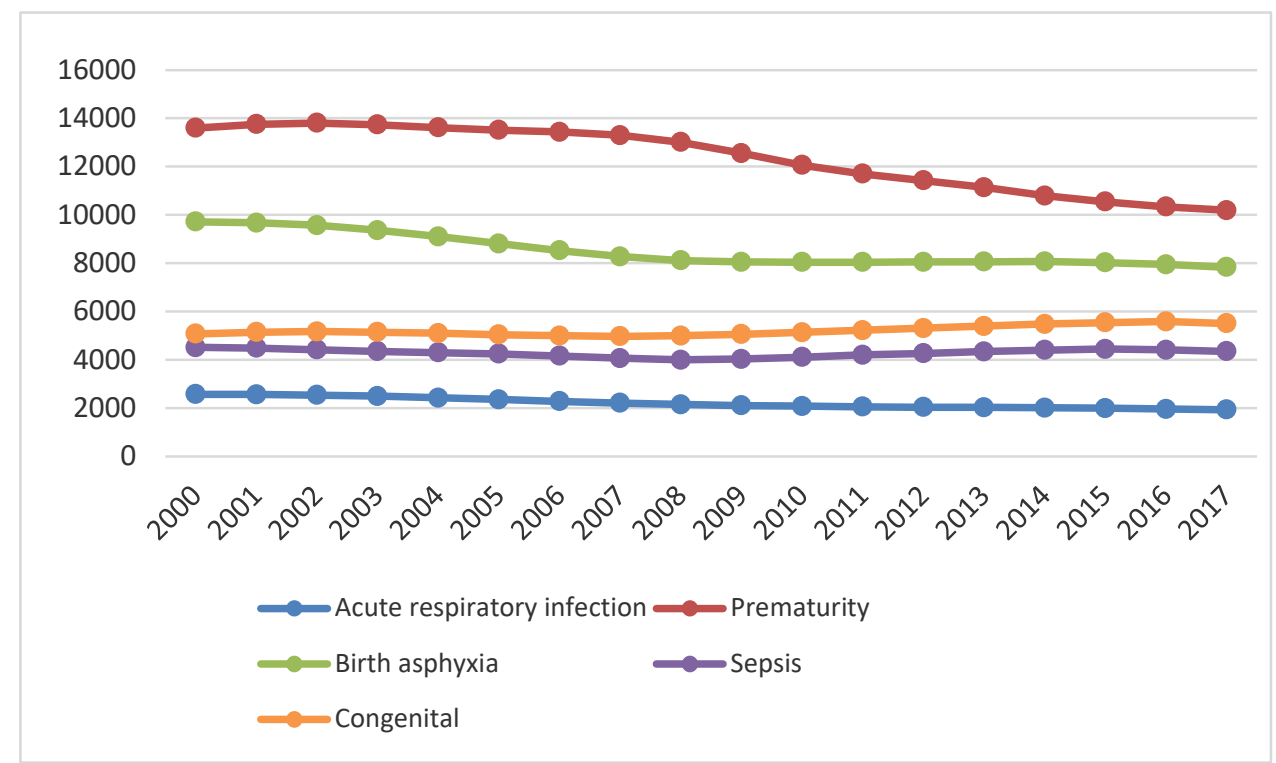

Figure 4.The leading causes of Neonatal Mortality in Philippines

Figure 5 illustrates the $f$ NMR in Myanmar from 2000 and 2017. Based on the data, it was found that premature birth was the most prevalent among the others (14.677 to 7197 ) followed by birth asphyxia (11.742 to 6.061) and ARI 2.930 to 1.417 ).

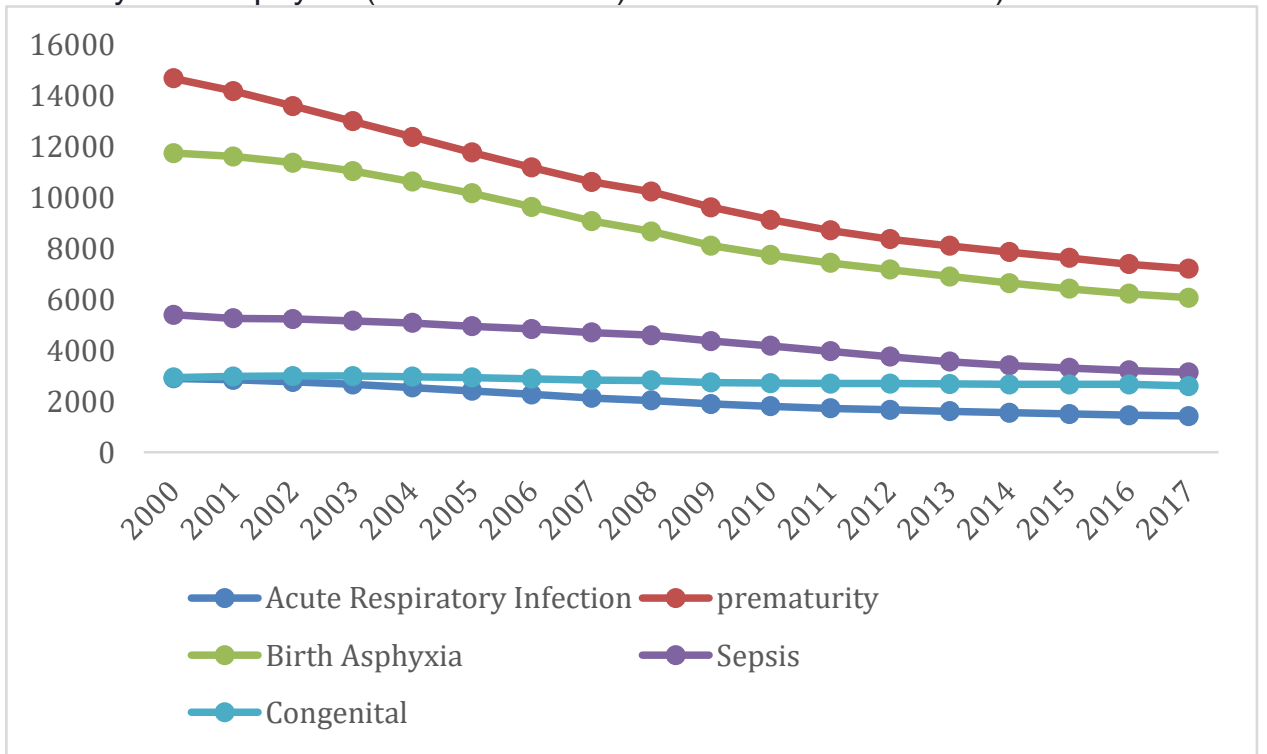

Figure 5.The leading causes of Neonatal Mortality in Myanmar

Figure 6 describes the NMR in Vietnam from 2000 to 2017. The graph indicates that premature birth was still the leading cause of NMR (8702 to 6728 ) followed by congenital anomaly (3915 to 3778 ), birth asphyxia (3306 to 2247), sepsis (1710 to 1369), and ARI (1960 to 1245). 


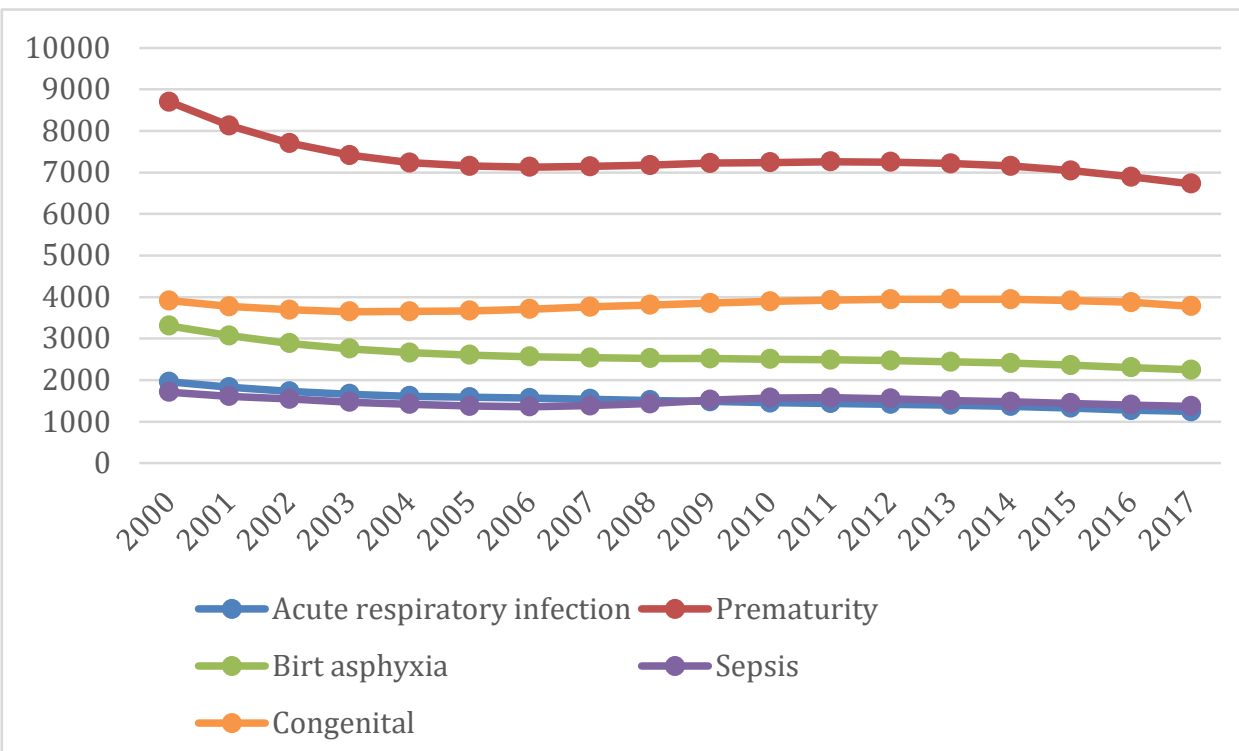

Figure 6. The leading causes of Neonatal Mortality in Vietnam

Similar to other countries in SEAC, the trend of NMR in Cambodia also declined between 2000 and 2017 as seen in Figure 7. Premature birth (3752 to 1699), birth asphyxia (3645 to 1261), and sepsis (1411 to 878 ) were the most prevalent among the causes while the lowest one was ARI (897 to 302).

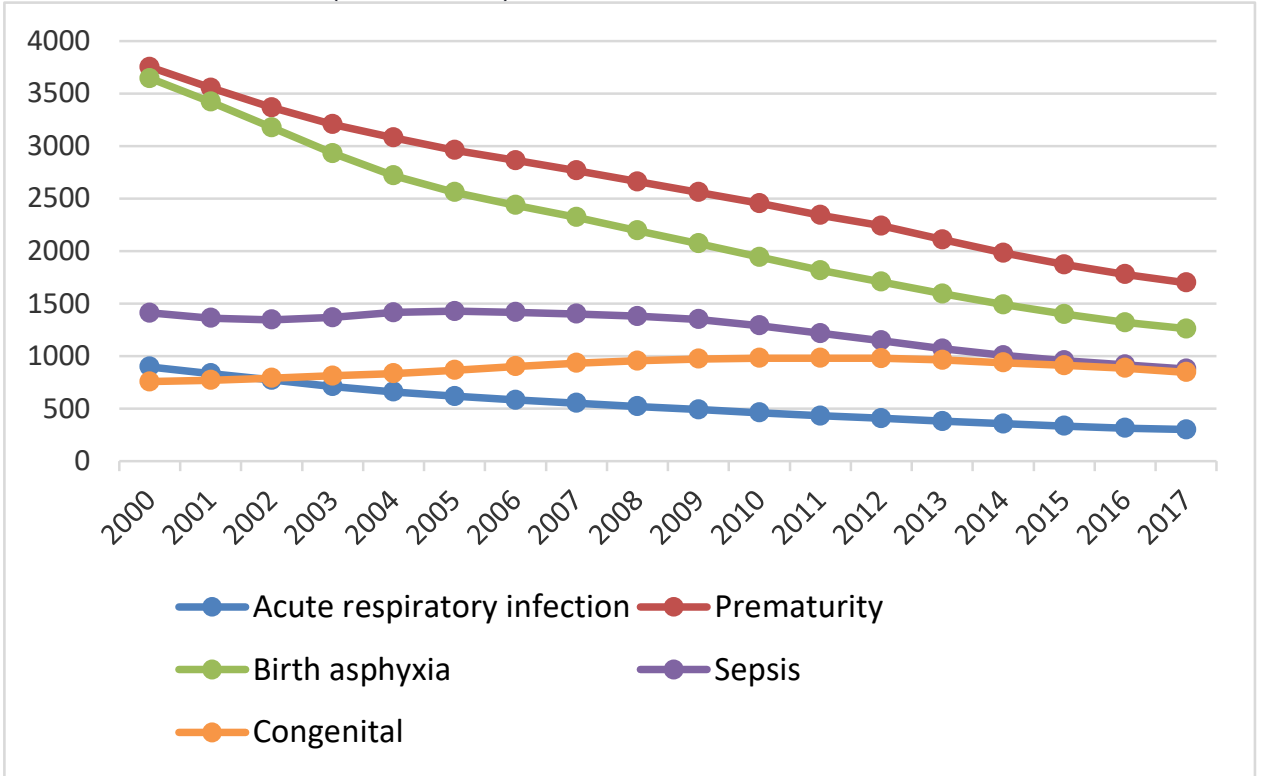

Figure 7.The leading causes of Neonatal Mortality in Cambodia

According to Figure 8, premature birth and birth asphyxia have also been the leading causes of NMR in Laos for 17 years. The leading causes were dominated by birth asphyxia (2164 to 1300), premature birth (1739 to 1300), sepsis (696 to 700), and ARI (583 to 322). 


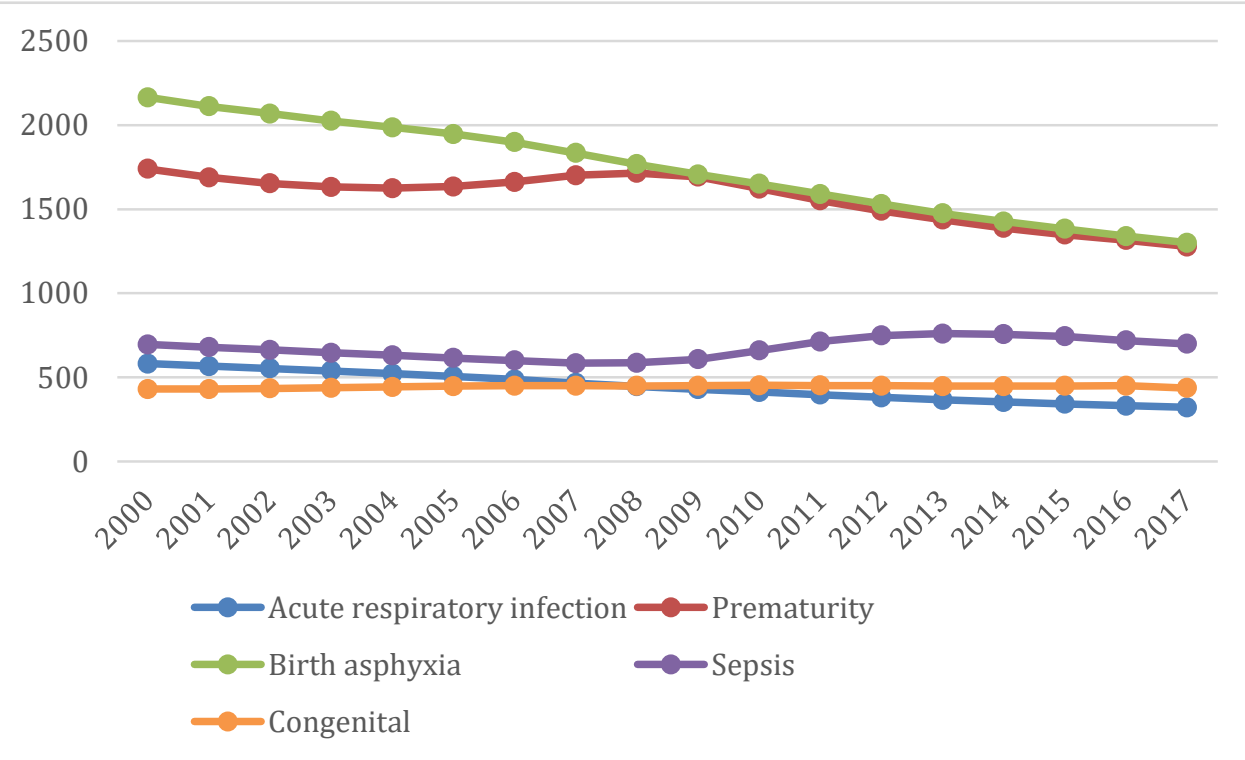

Figure 8.The leading causes of Neonatal Mortality in Laos

Figure 9 illustrates the number of leading causes NMR in Thailand from 2000 to 2017. It can be concluded that premature birth was the most dominant (4426 to 1404) followed by congenital defects (2305 to 960 ), birth asphyxia (1573 to 472 ), and sepsis (1065 to 236).

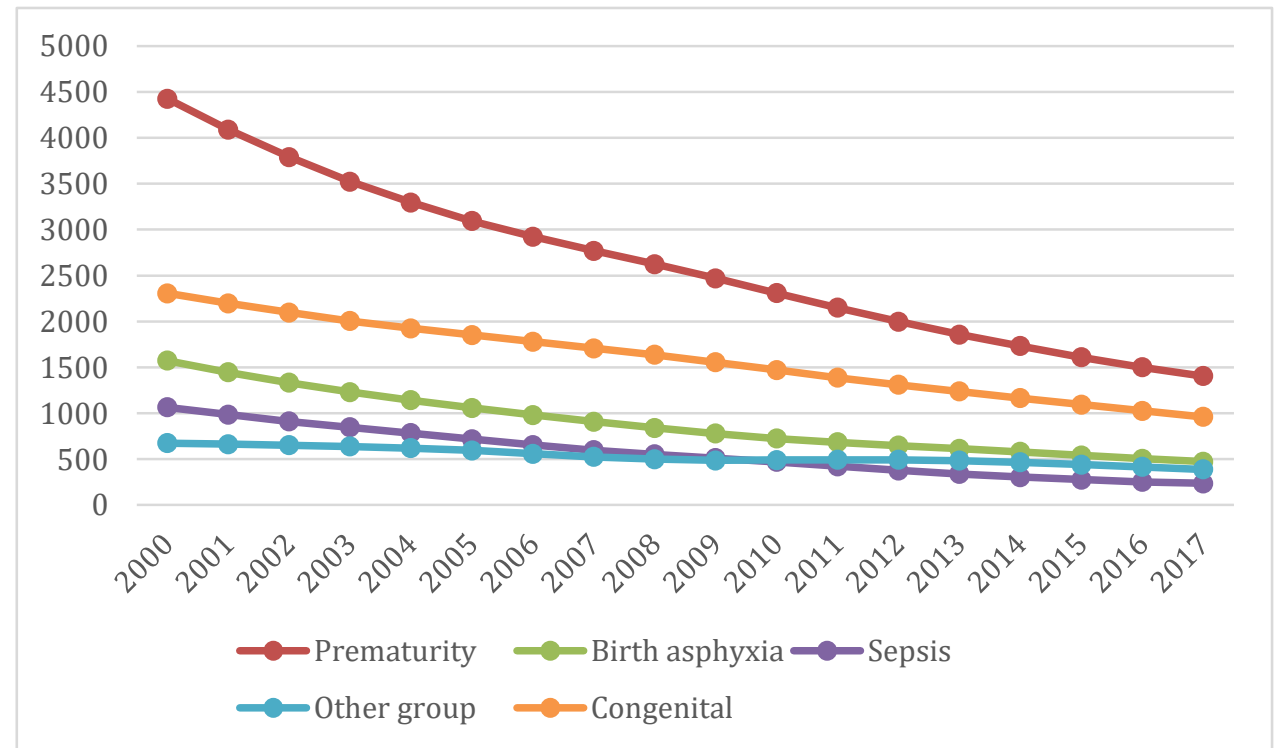

Figure 9.The leading causes of Neonatal Mortality in Thailand

Figure 10 shows that premature birth was the highest cause of NMR from 2000 to 2017 (1052 to 861) in Malaysia followed by congenital defects (759 to 621), birth asphyxia (414 to 287 ), and sepsis (240 to 176). 


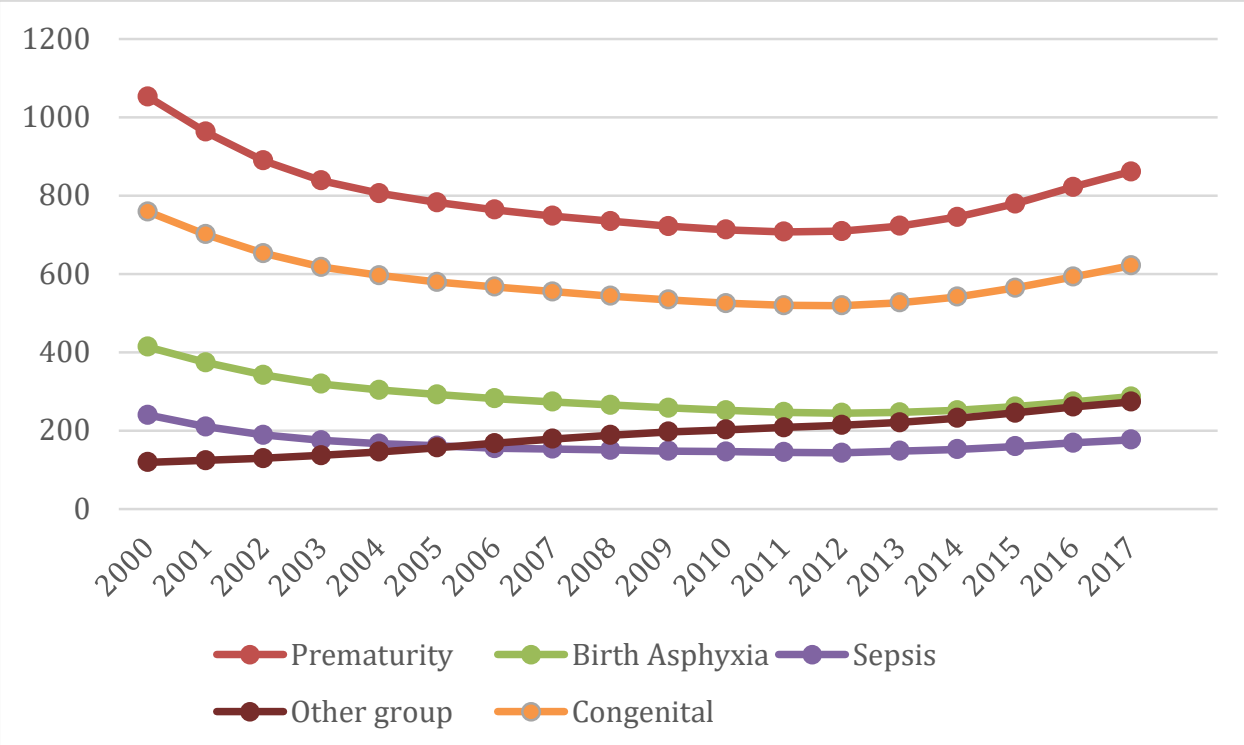

Figure 10.The leading causes of Neonatal Mortality in Malaysia

\subsection{Discussion}

According to the data from Center of Statistic Board (BPS) in 2012, the regions with the most prevalent infant mortality were West Nusa Tenggara (NTB), Gorontalo, Central Sulawesi, and West Papua provinces respectively (4). However, when the collective data was found, the NMR in Indonesia dropped slightly. The decrease of NMR started in 2003 when the community health insurance (Jaminan Kesehatan Masyarakat) was implemented for the first time. This program was strengthened by the delivery insurance (Jaminan Persalinan) in the next years $(11,12)$. As a result of the social health insurance program, the NMR in the next seven years significantly dropped by almost half from the beginning in 2000. The country with the second most prevalent NMR was Philippines. Similar to Indonesia, there was a declining of NMR since Philippine Health Insurance Program (PhilHealth) was applied in 1995. This health program was succeeded by "Health for All Filipino" program that focuses on the implementation of Universal Health Coverage (UHC). One of the goals of this program is enhancing primary care services that also concern maternal and neonatal safety issues. The successful policy was able to decrease the NMR in Phillippines (13).

Meanwhile, the NMR in Myanmar dropped due to the implementation of the health care program where the primary care embraced religion-based organization or social-based organizations to provide free health care services. Besides that, the Ministry of Health $(\mathrm{MoH})$ has a strong commitment to regulate health programs regarding environmental health, communicable and non-communicable disease, as well as mother and child health (14). As a result, there was a significant decline of NMR in Myanmar from 42,859 in 2000 to 22,625 in 2017. Furthermore, according to the graph one, the prevalence of NMR in Vietnam had started to drop from 2002, reaching the lowest trend for less than 20,000 in 2017. The government of Vietnam has been implementing National Standard Guidelines on Reproductive Health Services since 2003 and distributed it in entire health services providers to reduce neonatal mortality. The health care system in Vietnam were divided into four criteria namely commune, district, province, and central level where each of these having specific tasks to manage health care services including neonatal care (15). As the impact of the programs, the NMR declined from 20,878 in 2000 to 16,665 in 2012.

Between 2000 and 2015, the NMR in Cambodia declined from 43 to 19 per 1000 live birth. Similar to other countries, Cambodia has also established a health reform through its Health Strategic Plan 2008-2015. This strategic plan reinforces the accessibility of primary health care and increases the quality of human resources, particularly health workers to handle maternal, neonatal, child health, and degenerative diseases. The government has also regulated the distribution of health workers to nine priority health sector reform $(16,17)$. This program should be appreciated as it could decrease the NMR steadily from 12,031 in

The Trends of Neonatal Mortality Rate Among South East Asia.....(Sani Rachman Soleman) 
2000 to 5,458 in 2017. Laos, a small country where the number of population is estimated to be only seven million people, has its health policy focus on free services for antenatal care, postnatal care, and delivery services, as well as free health services for children under five (20). These health costs are financed by government and donor funding. There are four scheme of health financing in Laos namely Social Security Organization (SSO), State Authority for Social Security (SASS), Community Based-Health Insurance (CBHI), and Health Equity Fund (HEF)(20). The health policy in Laos was considered to be successful since it could decrease the NMR significantly from 6,800 in 2000 to 4,529 in 2017.

In Thailand, the image of NMR was quite similar to Cambodia. The implementation of universal health coverage through " 30 Baht scheme" for poor people to get health services access succeeded in decreasing the neonatal mortality up to 13 percent, reaching the lowest trend by 3,681 in 2017, almost one-third from 11,040 in 2000 was $(18,19)$. Malaysia has implemented a strategic plan in health care namely Malaysian Plan in 2004. This program emphasized the budget allocation for health care, distributed the skillful health workers to the rural area, and strengthened hospital and community health services to reduce neonatal mortality rate (21). However, it should be noticed that the trend of NMR in Malaysia slightly increased. Even though the result of the data was undesirable, the program is still running. As shown in the graph, the prevalence of NMR in Malaysia was 2,690 in 2000 and steadily increased to 3,681 in 2017. Unfortunately, there was no evaluation data related to the increasing of NMR in Malaysia.

Preterm birth is still a major public concern of government in SEAC followed by birth asphyxia and congenital anomalies. The leading causes of preterm birth in Indonesia were singleton pregnancy and head presentation. Although prematurity cases were high, regular antenatal care may lower the risk of preterm birth $(22,23)$. Meanwhile, birth asphyxia is correlated to ante partum bleeding, premature birth, pre-eclampsia, post mature and cesarean delivery (24). It is interesting that the trend for those factors started to decline along with the implementation of community health insurance and delivery insurance as mentioned above. In case of Philippine, the leading causes of NMR in the 2006-2007 survey were respiratory distress in newborn, bacterial sepsis, low birth weight, and asphyxia. It means prematurity and birth asphyxia were still the dominant causes of NMR based on the data in the survey compared to the data at the end of 2017 (31). The declining trend in Philippine could be attributed to the successful policy of PhilHealth program that focused on strengthening primary care (31).

In Myanmar, the most dominant leading cause of NMR were preterm birth and birth asphyxia. The declining NMR factors were linked to the successful health reform conducted by the government. The health reform in Myanmar assisted NGOs to support health finance and health services for poor people (14). The primary cause of NMR are premature birth and congenital anomalies caused by physically demanding work during pregnancy, abortion, history of preterm birth, vaginal bleeding, inadequate antenatal care, and intrauterine devices that are removed less than 12 months before current pregnancy. Meanwhile, the case of congenital disorders were dominated by limb defects, orofacial, and nervous system $(29,30)$. The case of NMR in Cambodia were dominated by premature birth as well as low birth weight. These were strongly linked to several factors such as maternal education background, first pregnancy, and antenatal care during pregnancy. Many pregnant women rarely visited healthcare services or clinic to get antenatal care (32). The occurrence of birth asphyxia in Cambodia was related to geographical area (urban and rural) and continuum care of maternal and wealth inequities (33). The declining of premature birth and asphyxia might be due to the successful policy of Health Strategic Plan 2008-2015, which comprised: optimization of primary healthcare; health services accessibility; empowering human resources to handle maternal, neonatal, child health, degenerative diseases; and the distribution for health care workers that focus on nine priority health sector reform $(16,17)$. The number of death due to birth asphyxia and premature birth in Laos were caused by maternal knowledge especially about safe pregnancy, nutritional support during pregnancy, and singleton pregnancy (34). The decreasing NMR in Laos was associated with the health policy that focused on free services for antenatal care, postnatal care, and delivery services. In addition, the health services for children under five would also be financed by the government and donor funding. The 
government had received funding and expanded the networking with Non-Governmental Organization (NGO) as many as possible to support maternal and neonatal health (20). In Thailand, the case of premature birth and congenital defects were the most prevalent. Maternal age, pre-pregnancy body mass index (BMI), prior history of preterm delivery, and no prenatal care were the major causes of preterm birth and congenital defects (27). According to WHO Southeast Asia Regional Office (SEARO) in 2013, congenital malformations in Thailand were dominated by heart defect, hemoglobin anomaly, nervous system defects, and genetic defect syndrome (28). The prevalence of NMR in Malaysia were dominated by premature birth and congenital anomalies caused by birth weight, multiple pregnancies, maternal age, and infant gender (25). The second biggest cause of NMR in Malaysia was congenital defect. The prevalence of congenital defects among the populations was cardiovascular, cleft lip, club feet, central nervous system, musculoskeletal, gastrointestinal system, and hydropsfetalis (26). Successful health policy program decreased the trend of NMR in Malaysia.

\section{Conclusion}

The trend of NMR in SEAC showed that Indonesia had the highest NMR while Philippine had the highest number of live birth. According to the data, premature birth, birth asphyxia, and congenital defect were the major causes of NMR. To decrease NMR, government and non-government organizations should take an integrated action to handle the primary causes of NMR that can be prevented b comprehensive and multi-sectoral approaches.

\section{References}

1. United Nation. Handbook for the preparation of voluntary national review. Department of Economic and Social Affairs United Nations; 2018.1-65 p.

2. United Nations. The sustainable development goals report 2016. United Nations; 2016.

3. Hug L, Sharrow D, Zhong K, You D, Ho J, RetnoMahanani W, et al.Levels \& Trends in Child Mortality - Report 2018. UN Inter-Agency Group for Child Mortatily Estimation; 2018. 1-45 p. https://www.unicef.org/publications/index 103264.html.

4. BadanPusatStatistik (BPS) Republik Indonesia. AngkaKematianBayimenurutprovinsi.https://www.bps.go.id/statictable/2009/02/20/1270/ang ka-kematian-bayi-menurut-provinsi-1971-1980-1990-1994-1997-2000-2002-2007-20102012-dan-kematian-dibawah-usia-lima-tahun-menurut-provinsi-1971-1980-1990-19941997-1999-2007-dan-2012-.html.

5. Tran H, Doyle L, Lee K, Graham S. A systematic review of the burden of neonatal mortality and morbidity in the ASEAN Region. J Public Heal. 2017;1(3):239.

6. Hug L, Alexander M, You D, Alkema L. National, regional, and global levels and trends in neonatal mortality between 1990 and 2017, with scenario-based projections to 2030: a systematic analysis. Lancet Glob Heal. 2019;7(6):e710-20.

7. Russo LX, Scott A, Sivey P, Dias J. Primary care physicians and infant mortality: Evidence from Brazil. PLoS One. 2019;14(5):1-16.

8. Lambon-Quayefio M, Owoo NS. Determinants and the impact of the National Health Insurance on neonatal mortality in Ghana. Health Econ Rev. 2017;7(1).

9. Ahmed M, Won Y. Cross-national systematic review of neonatal mortality and postnatal newborn care: Special focus on Pakistan. Int J Environ Res Public Health. 2017;14(12).

10. World Health Organization. Improving Early Childhood Development: WHO Guideline 2020; 2020.https://www.who.int/publications-detail/improving-early-childhood-development-whoguideline

11. Yusuf E, Awaaliyah I. The implementation of Indonesian National Health Insurance Programme: How Satisfiedwere The Insured Participants and The Healtcare Providers. Journal of Consumer Sciences. 2018;3(2):27-42.

12. Sambodo P. The Impact of Jamkesmas on Healthcare Utilization in Eastern Regions of Indonesia: a Propensity Score Matching Method.JurnalEkonomi\&Studi Pembangunan. 2018;19(2):116-133.

13. Europea Union. The Philippines Health System Review. Health systems in transition2018;8(2):183-206. 
14. Latt NN, Cho SM, Mie Htun NM, Myint MNHA, Aoki F, Reyer JA, et al. Healthcare in Myanmar. Nagoya J Med Sci. 2016;78(2):123-34.

15. Lee HY, Do DV, Choi S, Trinh OT, To KG. Trend and determinants of infants and underfive childhood mortality in Vietnam, 1986-2011. Glob Health Action. 2016;9:1-10.

16. Suy R, Yen Y, Mian M. Cambodian Healthcare policy: Challenges and Development.ljhassnet. 2017;2(2):23-32.

17. Tangcharoensathien V. The Kingdom of Cambodia Health System Review. Health Syst Transit. 2015;5(2):1-178.

18. Paek CS, Meemon N, Wan T. Thailand's Universal Coverage Scheme and It's Impact on Health-Seeking Behaviour.Springerplus. 2016;5(1):1-16.

19. Sumriddetchkajorn K, Shimazaki K, Ono T, Kusaba T, Kobayashi N. Universal Health Coverage and Primary Care, Thailand. Bull World Health Organ. 2019;97(6):415-422.

20. Bodhisane S, Pongpanich S. The Impact of National Health Insurance upon Accessibility of Health Services and Financial Protection from Catasthropic Health Expenditure: A Case Study of Savannakhet Province, the Lao People's Democratic Republic. Health Res Policy Syst. 2019;17(99):1-14.

21. Croke K, Yusoff M, Abdullah Z, Hanafi A, Mokhtarudin M, Ramli E, et al. The Political Economy of Health Financing Reform in Malaysia. Health Policy Plan. 2019;34(10):732739.

22. Howell E. Reducing Disparities in Severe Maternal Morbidity and Mortality. ClinObstet Gynecol. 2018;61(2):387-399.

23. Sungkar A, Fattah ANA, Surya R, Santoso BI, Zalud I. High preterm birth at CiptoMangunkusumo Hospital as a national referral hospital in Indonesia. Med $J$ Indones. 2017;26(3):198.

24. Anggondowati T, Mohandes A, Qomariyah N, Kiely M, Ryon J, Gipson R. Maternal Characteristic and Obstretical Complication Impact Neonatal Outcomes in Indonesia: A Prospective Study. BMC Pregnancy Childbirth. 2017;17(100):1-12.

25. Sutan R, Mohamed NE, Mahdy ZA, Ishak S, Shamsuddin K, Badillaldris I, et al. A 5 year trend and predictors of preterm births in single referral centre of the Greater Kuala Lumpur, Malaysia. Int J Pregnancy Child Birth. 2018;4(6):196-201.

26. Mat B, Sapian M, Jamil M, Abdullah N, Alias E, Zahari N. The Birth Prevalence, Severity and Temporal Trends of Congenital Heart Disease in the Middle-Income Country: A Populatin Based Study. Congenital Heart Disease. 2018:1-16.

27. Samejima T, Nagamatsu T, Iriyama T, Nakayama T, Seyama T, Sayama S, et al.Impact of additional risk factors on the incidence of preterm delivery among pregnant women diagnosed with short cervix.Taiwanese Journal of Obstetrics and Gynecology. 2020;59(2):195-199.

28. Zhou Y, Mao X, Zhou H, Qin Z, Wang L, Cai Z, et al. Epidemiology of Birth Defect Based on Birth Defect Surveillence System in Southern Jiangsu, China, 2014-2018. The Journal of Maternal Fetal\& Neonatal Medicine. 2020:1-7.

29. Giang H, Pozza S, Hoang T, Ulrich S. Stillbirth and Preterm Birth and Associated Factors in One of The Largest Cities in Central Vietnam. ActaPediatrica. 2018:1-23.

30. Miles M, Dung K, Ha L, Liem N, Ha K, Hunt R, et al. The Cause Specific Morbidity and Mortality and Referral Patterns of All Neonates Admitted to A Tertiary Referral Hospital in the Northern Provinces of Vietnam Over A One Year Period. Plos One. 2017;12(3)1-12.

31. Wang H., Global, Regional, National, and Selected Subnational Level of Stillbirths, Neonatal, Infants and Under-five Mortality, 1980-2015: A Systematic Analysis for the Global Burden of Disease Study 2015. Lancet. 2016;388:1725-1774.

32. Chhea C, Ir P, Sopheab H. Low birth weight of institutional births in Cambodia: Analysis of the demographic and health surveys 2010-2014. PLoS One.2018;13(11):1-16.

33. Hong R, Ahn PY, Wieringa F, Rathavy T, Gauthier L, Hong R, et al. The unfinished health agenda: Neonatal mortality in Cambodia. PLoS One. 2017;12(3):4-6.

34. Olsen S, Vetsaphong P, Vonglokham P, Mirza S, Khanthamaly V, Chanthalangsy T, et al. A Retrospective Review of Birth Outcome at the Mother and Child Health Hospital in Lao People's Democratic Republic, 2000-2013. BMC Pregnancy and Childbirth. 2016;16(379): 1-6.

Disease Prevention and Public Health Journal

Volume 14, Issue 2, September 2020: $90 \sim 100$ 